https://nv.nltu.edu.ua

https://doi.org/10.36930/40300215

$@ \bowtie$ Correspondence author

Article received 31.03.2020 p.

Article accepted 04.06.2020 p.

M. I. Herys

UDC 629.113

mherys@ukr.net

Г. С. Гудз', М. І. Герис ${ }^{2}$, I. Я. Захара ${ }^{3}$, М. М. Осташук ${ }^{1}$

${ }^{1}$ Національний університет "Львівська політехніка", м. Львів, Україна

${ }^{2}$ Національний лісотехнічний університет Украйни, м. Львів, Украйна

${ }^{3}$ Івано-Франківський наиіональний технічний університет нафти і газу, м. Івано-Франківськ, Украйна

\title{
МОДЕЛІ ВИЗНАЧЕННЯ ВПЛИВУ ВМІСТУ ВУГЛЕЦЮ В ЕЛЕКТРОДІ НА ВЛАСТИВОСТІ ДЕТАЛЕЙ МАШИН ПІД ЧАС ВІБРОДУГОВОГО НАПЛАВЛЕННЯ
}

Для відновлення ресурсу деталей машин широко застосовують різні способи наплавлення їхніх поверхонь. Встановлено, що найкращі результати показують способи вібродугового наплавлення через слабкий нагрів відновлюваної деталі, незначну величину термічного впливу, внаслідок чого хімічний склад та фізико-механічні властивості деталі майже не змінюються. 3'ясовано, що застосуванням електродного дроту з відповідним вмістом вуглецю можна отримати всі види загартованих структур наплавленого металу, який характеризується достатньо високою твердістю та зносостійкістю. Виявлено, що структура та твердість наплавленого металу виходить неоднорідною, на межі оплавлення деяких валиків трапляються пори й мікротріщини. Великі внутрішні розтягувальні напруження, що виникають у покритті, й дефекти структури, у вигляді пор та мікротріщин, різко знижують втомну міцність деталей, що працюють за знакозмінних навантажень. Тому у роботі наведено результати досліджень, які показують залежність втомної міцності і твердості поверхні деталі під час наплавлення зразків електродом з різним вмістом вуглецю без охолоджувальної рідини (в атмосфері повітря та вуглекислого газу) і 3 охолоджувальною рідиною за подачі її на наплавлюваний зразок на різних режимах. Ці залежності відображають зв'язок між досліджуваними змінними і можуть бути подані у вигляді математичних моделей, які бувають лінійними та нелінійними. Для отримання моделі за певним алгоритмом опрацьовано масиви вхідних і вихідних даних, для яких методом найменших квадратів визначено числові значення коефіцієнтів моделі. Опрацювання емпіричних залежностей твердості поверхні наплавлених зразків від вмісту вуглецю в електроді дало змогу побудувати лінійну модель, а для втомної міцності деталі від вмісту вуглецю - параболічну. Розраховані коефіцієнти кореляції підтвердили достовірний характер отриманих моделей для визначення впливу вмісту вуглецю в електроді на твердість поверхні та втомну міцність деталі.

Ключові слова: відновлення деталей машин; наплавлення поверхонь деталей; твердість поверхні; втомна міцність деталі; лінійні й нелінійні математичні моделі.

Вступ. Підвищення експлуатаційних показників машин значно залежить від своєчасного проведення ремонтних робіт. Для зменшення витрат на ремонт та його якісного проведення необхідно використовувати ефективні способи відновлення деталей, які дають змогу підвищити їхній ресурс. До таких варто віднести вібродугове наплавлення деталей $[1,8]$.

Дослідження з відновлення деталей виконували досить давно, через перерву, спричинену реструктуризацію авторемонтної галузі. Сьогодні ситуація змінилась, про що свідчать роботи $[3,4,6,7,9]$, в яких ретельно досліджено як позитивні моменти, так і негативні наслідки процесів відновлення деталей. Стосовно вібродугового наплавлення деталей, то до позитиву варто віднести їхню підвищену зносостійкість, а до негативних явищ - появу пор та тріщин, що знижують втомну міц-

ність деталей. На ці властивості деталі значною мірою впливає вміст вуглецю в електроді та режим проведення вібродугового наплавлення, що й визначає актуальність цього дослідження.

Об'єкт дослідження - процес вібродугового наплавлення деталей машин.

Предмет дослідження - методи і засоби визначення закономірностей впливу вмісту вуглецю в електроді на механічні властивості деталей під час вібродугового наплавлення.

Мета дослідження - створити математичні моделі визначення впливу вуглецю в електроді на механічні властивості деталей під час вібродугового наплавлення.

Основним завданням роботи - експериментально дослідити вплив вмісту вуглецю в електроді на механічні властивості деталей під час вібродугового наплавлення та математично описати ці залежності.

Інформація про авторів:

Гудз Густав Степанович, д-р техн. наук, професор, кафедра експлуатації та ремонту автомобільної техніки. Email: ggudz@polynet.Iviv.ua

Герис Микола Іванович, канд. техн. наук, доцент, кафедра лісових машин. Email: mherys@ukr.net

Захара Irop Ярославович, канд. техн. наук, доцент, кафедра автомобільного транспорту. Email: texnikigor83@gmail.com

Осташук Микола Михайлович, канд. техн. наук, доцент, кафедра транспортних технологій. Email: mikola.ostashuck.m@gmail.com

Цитування за Дсту: Гудз Г. С., Герис М. І., Захара І. Я., Осташук М. М. Моделі визначення впливу вмісту вуглецю в електроді на властивості деталей машин під час вібродугового наплавлення. Науковий вісник НлтУ України. 2020, т. 30, № 2. С. 83-87.

Citation APA: Gudz, G. S., Herys, M. I., Zakhara, I. la., Ostashuk, M. M. (2020). Models for determining the effect of carbon content in the electrode on the properties of machine parts during electric arc cladding. Scientific Bulletin of UNFU, 30(2), 83-87. https://doi.org/10.36930/40300215

Науковий вісник НЛТУ України, 2020, т. 30, № 2

Scientific Bulletin of UNFU, 2020, vol. 30, no 2 
Наукова новизна полягає у створенні, на підставі емпіричних досліджень, математичних моделей визначення впливу вмісту вуглецю в електроді на механічні властивості деталей машин у процесі вібродугового наплавлення.

Практична цінність отриманих результатів дослідження становлять в основному для технологів ремонтного виробництва під час розроблення технологічних процесів відновлення деталей машин.

Матеріал і методи дослідження. Оскільки хімічний склад, структура, твердість і міцність наплавленого шару залежать переважно від хімічного складу електродного дроту, то для дослідження було вибрано 50 зразків пруткової сталі 45 після нормалізації. Електродний дріт відповідав вмісту вуглецю у сталях 0,08 , 0,3, 0,5, 0,8 та 1,2\%. Дослідження виконували на ремонтній базі ТзОВ "ЛВ-ТРАНС-АВТО", м. Дубляни.

Під час виконання цього дослідження використано методи емпіричного та експериментально-теоретичного досліджень, а також методи математичної статистики.

Результати дослідження. На рис. 1 наведено криві втомної міцності зразків, наплавлених в атмосфері повітря і в середовищі вуглекислого газу, а також у рідині, за різного вмісту вуглецю у дроті. Як видно з наведених кривих, за вмісту вуглецю у дроті 1,17 \% втомна міцність під час наплавлення без охолоджувальної рідини та 3 рідиною є приблизно однаковою, що не можна сказати про твердість.

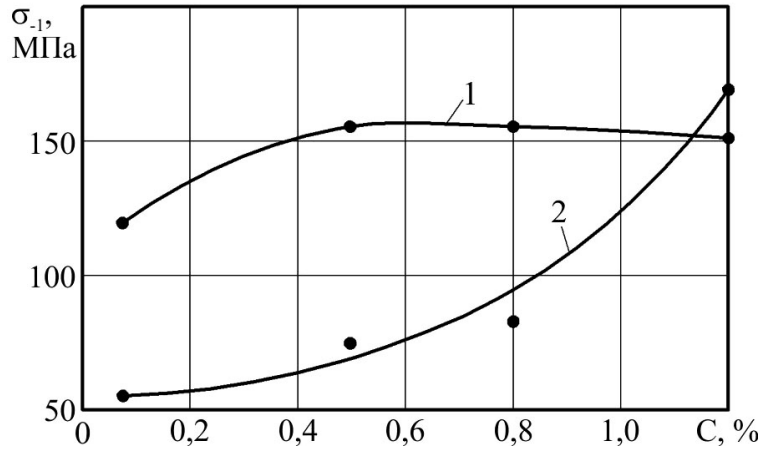

Рис. 1. Криві втомної міцності наплавлених зразків залежно від вмісту вуглецю в електродному дроті: 1) під час наплавлення без рідини; 2) під час наплавлення з охолоджувальною рідиною

Отримані залежності твердості наплавленого металу від вмісту вуглецю в електродному дроті під час наплавлення без охолоджувальної рідини та 3 рідиною наведено на рис. 2. Як видно з цього рисунку, з підвищенням вмісту вуглецю у дроті твердість наплавленого металу зростає під час наплавлення як без рідини, так і зі застосуванням охолоджувальної рідини, до того ж в останньому випадку твердість наплавленого шару отримуємо значно вищою. Це пояснюють збагаченням наплавленого шару вуглецем основного металу (сталі 45) й, як наслідок, загартуванням наплавленого шару. Мікроструктура металу, наплавленого дротом 3 різним вмістом вуглецю, без застосування рідини, отримана порівняно однорідною.

Проведений аналіз емпіричних залежностей, наведених на рис. 2, дає підстави припустити гіпотезу про лінійну залежність між твердістю наплавлених зразків $y$ та вмістом вуглецю в електроді $x$, тобто побудувати лінійну модель

$$
\hat{y}(x)=b_{0}+b_{1} x
$$

де: $b_{0}-$ вільний член; $b_{1}-$ коефіцієнт впливу $x$ на $y$.

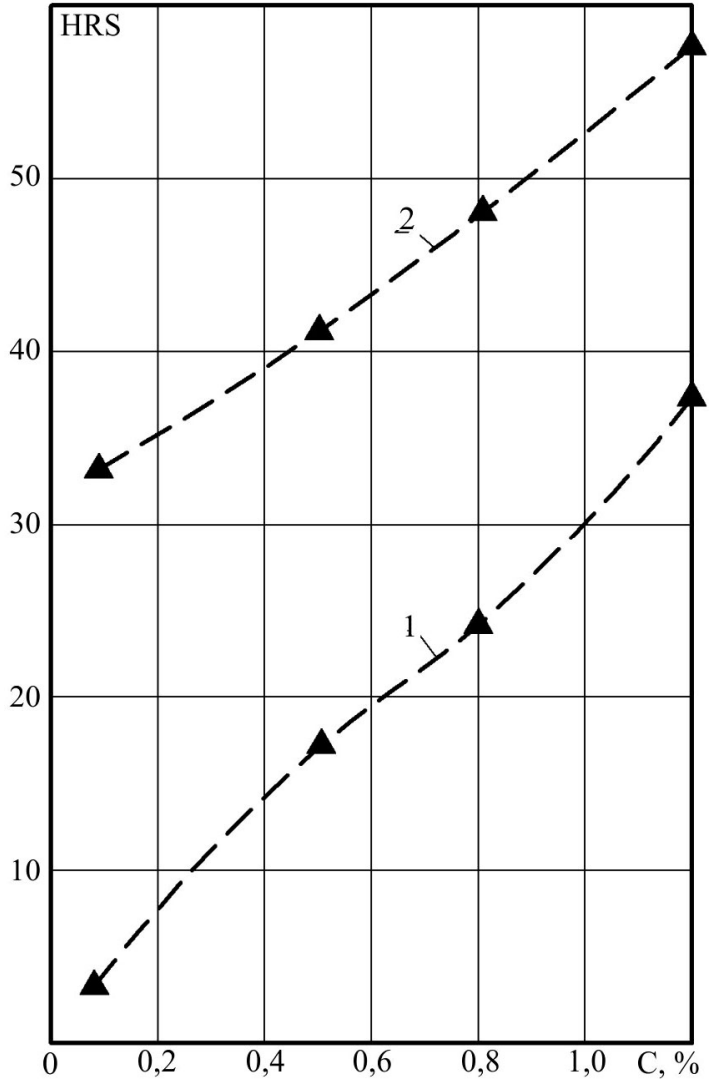

Рис. 2. Криві твердості наплавлених зразків залежно від вмісту вуглецю у дроті: 1) під час наплавлення без рідини; 2) під час наплавлення $з$ охолоджувальною рідиною

Для отримання моделі потрібно за певним алгоритмом опрацювати масиви вхідних $x_{i}$ та вихідних даних $y_{i}$, де $i=n$ ( $n$ - кількість експериментів) і визначити числові значення $b_{0}$ і $b_{1}$.

Для визначення коефіцієнтів $b_{0}$ та $b_{1}$ застосовують метод найменших квадратів $[2,5]$. Суть його полягає в такому: якщо на площині $x y$ нанести точки $x_{i}, y_{i}, i=n$, то потрібно провести пряму лінію $\hat{y}(x)$ так, щоб відхилення $y_{i}$ від цієї лінії відповідали умові

$$
\begin{gathered}
F=\sum_{i=1}^{n}\left[y_{i}-\hat{y}\left(x_{i}\right)\right]^{2}=\min . \\
\sigma_{E}^{2}=\frac{F}{n}=\frac{1}{n} \sum_{i=1}^{n}\left[y_{i}-\hat{y}\left(x_{i}\right)\right]^{2},
\end{gathered}
$$

Якщо

то ця умова слугує статистичною оцінкою точності моделі.

Для виконання умови (1) потрібно взяти похідну від $F$ за параметрами $b_{0}$ та $b_{1}$ та прирівняти до нуля. Отримані значення $b_{0}$ i $b_{1}$ задовольнятимуть умову (1).

Отже:

$$
\begin{gathered}
F=\sum_{i=1}^{n}\left[y_{i}-\left(b_{0}+b_{1} x_{i}\right)\right]^{2} ; \\
\left\{\begin{array}{l}
\frac{d F}{d b_{0}}=2 \sum_{i=1}^{n}\left[y_{i}-\left(b_{0}+b_{1} x_{i}\right)\right]=0 ; \\
\frac{d F}{d b_{1}}=2 \sum_{i=1}^{n}\left[y_{i}-b_{0}+b_{1} x_{i}\right] x_{i}=0 .
\end{array}\right.
\end{gathered}
$$

Запишемо рівняння для визначення $b_{0}$ та $b_{1}$

$$
\left\{\begin{array}{l}
b_{0} n+b_{1} \sum_{i=1}^{n} x_{i}=\sum_{i=1}^{n} y_{i} ; \\
b_{0} \sum_{i=1}^{n} x_{i}+b_{1} \sum_{i=1}^{n} x_{i}^{2}=\sum_{i=1}^{n} x_{i} y_{i} .
\end{array}\right.
$$


Розв'язок цієї системи відносно $b_{0}$ та $b_{1}$, за допомогою правила Крамера дає змогу отримати оптимальні значення коефіцієнтів [2]

$$
b_{1}=\frac{\left(\sum_{i=1}^{n} x_{i} \sum_{i=1}^{n} y_{i}\right)-n \sum_{i=1}^{n} x_{i} y_{i}}{\left(\sum_{i=1}^{n} x_{i}\right)^{2}-n \sum_{i=1}^{n} x_{i}^{2}}, b_{0}=\frac{1}{n}\left(\sum_{i=1}^{n} y_{i}+b_{1} \sum_{i=1}^{n} x_{i}\right) .
$$

Після розрахунку коефіцієнтів моделей потрібно провести її оцінку, тобто розрахувати статистичну точність отриманої моделі та перевірити гіпотезу про лінійність зв'язку між змінними $y$ та $x$.

Для цього потрібно розрахувати: загальну дисперсію $\sigma_{y}^{2}-$ коливань $y_{i}$ відносно середнього значення $\bar{y}=\frac{1}{n} \sum_{i=1}^{n} y_{i}$, тобто

$$
\sigma_{y}^{2}=\frac{1}{n} \sum_{i=1}^{n}\left(y_{i}-\bar{y}\right)^{2}
$$

- факторну дисперсію $\sigma_{\hat{y}}^{2}$, що відображає вплив тільки тих змінних, які входять у модель

$$
\sigma_{\hat{y}}^{2}=\frac{1}{n} \sum_{i=1}^{n}\left(\hat{y}_{i}-\bar{y}\right)^{2}
$$

і оцінює розсіювання розрахункових значень $\hat{y}$ відносно $\bar{y}$;
- залишкову дисперсію $\sigma_{0}^{2}$, що оцінює розсіювання експериментальних даних $y_{i}$ відносно розрахункових даних моделі $\hat{y}_{i}$ і яка характеризує статистичну похибку моделі

$$
\sigma_{0}^{2}=\frac{1}{n} \sum_{i=1}^{n}\left(y_{i}-\bar{y}\right)^{2} \text { або } \sigma_{0}^{2}=\sigma_{y}^{2}-\sigma_{\hat{y}}^{2} .
$$

Відношення $\quad K_{д}=\frac{\sigma_{\hat{y}}^{2}}{\sigma_{y}^{2}}$

називають коефіцієнтом детермінації, яке характеризує частку впливу вибраних змінних $x_{i}$ у загальній дисперciï $\sigma_{y}^{2}$.

Величину $\quad R=\sqrt{K_{D}}=\sqrt{\frac{\sigma_{y}^{2}-\sigma_{o}^{2}}{\sigma_{y}^{2}}}=\sqrt{1-\frac{\sigma_{o}^{2}}{\sigma_{y}^{2}}}$

називають коефіцієнтом кореляції. Вона характеризує щільність зв'язку між змінними $x$ та $y$, тобто дає змогу перевіряти гіпотезу про лінійність зв'язку між ними. Чим ближче значення $R$ до одиниці, тим вірогідніша лінійність $y(x)$. Практично приймаємо, що якщо $R \geq 0,7$, то така модель достатньо повно відображає вплив чинників.

У табл. 1 наведено дані, необхідні для визначення коефіцієнтів моделі за допомогою методу найменших квадратів.

Табл. 1. Початкові дані для визначення коефіціснтів моделі

\begin{tabular}{|c|c|c|c|c|c|c|c|}
\hline \multicolumn{4}{|c|}{$\hat{y}=b_{0}+b_{1} x$ наплавлення без рідини } & \multicolumn{3}{c|}{$\hat{y}_{2}=b_{0}{ }^{\prime}+b_{1}{ }^{\prime} x$ наплавлення з охолоджувальною рідиною } \\
\hline$x_{i}$ & $x_{i}^{2}$ & $y_{1 i}$ & $y_{1 i} x_{i}$ & $x_{i}$ & $x_{i}^{2}$ & $y_{2 i} x_{i}$ & $y_{2 i}$ \\
\hline 0,08 & 0,0064 & 3,4 & 0,272 & 0,08 & 0,0064 & 2,67 & 33,4 \\
\hline 0,5 & 0,25 & 16,5 & 8,25 & 0,5 & 0,25 & 21,0 & 42,0 \\
\hline 0,8 & 0,64 & 24,0 & 19,2 & 0,8 & 0,64 & 38,4 & 48,0 \\
\hline 1,2 & 1,44 & 37,5 & 45,0 & 1,2 & 1,44 & 64,0 & 57,5 \\
\hline 2,58 & 2,336 & 81,4 & 72,722 & 2,58 & 2,336 & 131,07 & 180,9 \\
\hline
\end{tabular}

Табл. 2. Початкові дані для розрахунку дисперсії

\begin{tabular}{|c|c|c|c|c|c|c|c|c|c|c|c|}
\hline \multicolumn{9}{|c|}{$\hat{y}_{1}=0,95+30,7 x$} & \multicolumn{5}{c|}{$\hat{y}_{2}=31,4+21,41 x$} \\
\hline$y_{i}$ & $\hat{y}_{1 i}$ & $y_{i}-\bar{y}$ & $\left(y_{i}-\bar{y}\right)^{2}$ & $y_{i}-\hat{y}_{1 i}$ & $\left(y_{i}-\hat{y}_{1 i}\right)^{2}$ & $y_{i}$ & $\hat{y}_{2 i}$ & $y_{i}-\bar{y}$ & $\left(y_{i}-y\right)^{2}$ & $y_{i}-\hat{y}_{2 i}$ & $\left(y_{i}-\hat{y}_{2 i}\right)^{2}$ \\
\hline 3,4 & 3,36 & $-16,95$ & 287,30 & 0,04 & 0,0016 & 33,4 & 33,1 & 11,8 & 139,83 & 0,3 & 0,09 \\
\hline 16,5 & 16,0 & $-3,85$ & 14,82 & 0,5 & 0,25 & 42 & 42,1 & $-3,2$ & 10,40 & $-0,1$ & 0,01 \\
\hline 24 & 25,0 & 3,65 & 13,32 & 1 & 1 & 48 & 48,5 & 2,8 & 7,70 & $-0,5$ & 0,25 \\
\hline 37,5 & 37,03 & 17,75 & 294,12 & 0,47 & 0,2209 & 57,5 & 57,9 & 12,3 & 150,68 & 0,41 & 0,1681 \\
\hline 81,4 & - & - & 609,57 & - & 1,4963 & 180,9 & - & - & 308,61 & - & 0,5378 \\
\hline \multicolumn{3}{|c|}{$\hat{y}=\frac{1}{4} \sum_{i=1}^{n} y_{i}=\frac{81,4}{4}=20,35$} & \multicolumn{7}{c|}{$\hat{y}=\frac{180,9}{4}=45,2$} \\
\hline
\end{tabular}

Коефіцієнти моделі розраховуємо, використовуючи формули (2):

$$
\begin{gathered}
b_{1}=\frac{81,4 \cdot 2,58-4 \cdot 72,722}{2,58^{2}-4 \cdot 2,336}=\frac{-80,876}{-2,6892}=30,07 ; \\
b_{0}=\frac{1}{4}(81,4-30,07 \cdot 2,58)=\frac{1}{4}(81,4-77,59)=\frac{3,81}{4}=0,95 .
\end{gathered}
$$

Тоді $\hat{y}_{1}=0,95+30,07 x$.

Для моделі $\hat{y}_{2}=b_{0}+b_{1} x$ :

$$
\begin{gathered}
b_{1}^{\prime}=\frac{2,58 \cdot 180,9-4 \cdot 131,072}{2,58^{2}-4 \cdot 2,336}=\frac{-57,568}{-2,689}=21,41 ; \\
b_{0}^{\prime}=\frac{1}{4}(180,9-21,41 \cdot 2,58)=\frac{1}{4}(180,9-55,26)=\frac{125,64}{4}=31,4 ; \\
\hat{y}_{2}=31,4+21,41 x .
\end{gathered}
$$

Для оцінювання якості отриманих моделей розраховуємо коефіцієнти кореляції і детермінації (3) та (4).

У табл. 2 наведено дані для розрахунку загальної $\sigma_{y}^{2}$ та факторної $\sigma_{\hat{y}}^{2}$ дисперсій, щоб оцінити точність отриманих моделей.
Тоді розраховуємо $R_{1}$ при відомих дисперсіях: $\sigma_{y 1}^{2}=609,57 ; \sigma_{0}^{2}=1,4963 ; \sigma_{\hat{y} 1}^{2}=609,57-1,4963=608,07$,

$$
R_{1}=\sqrt{\frac{\sigma_{\hat{y} 1}^{2}}{\sigma_{y 1}^{2}}}=\sqrt{\frac{608,07}{609,57}}=\sqrt{0,997}=0,998,
$$

а коефіцієнт детермінації $K_{д}=0,997$.

Оскільки $R_{1}=0,998>0,7$, то зв'язок між досліджуваними змінними достатньо щільний і залежність $y(x)$ близька до лінійної.

Для моделі $\hat{y}_{2}(x)$ :

$$
\begin{gathered}
\sigma_{y 2}^{2}=308,61 ; \sigma_{0}^{2}=0,5378 ; \sigma_{\hat{y} 2}^{2}=308,61-0,5378=308,07 . \\
R_{2}=\sqrt{\frac{308,07}{308,61}}=\sqrt{0,998}=0,999 .
\end{gathered}
$$

Оскільки $R_{2}>0,7$, то гіпотеза про лінійність моделі правильна і зв'язок між змінними щільний.

На рис. 1 наведено криві втомної міцності наплавлених зразків залежно від вмісту вуглецю в електроді під 
час наплавлення без рідини (1) та 3 охолоджувальною рідиною (2). Аналіз цих залежностей дає підстави припустити, що залежність між змінними $y(x)$ - степенева функція

$$
\hat{y}=a x^{b} .
$$

Ця модель нелінійна, проте іiі можна звести до лінійної форми логарифмуванням

$$
y=a x^{b} \Rightarrow \lg y=\lg a+b \lg x \Rightarrow y^{\prime}=a^{\prime}+b x^{\prime}
$$

і тоді модель матиме вигляд

$$
\hat{y}^{\prime}=a^{\prime}+b x^{\prime} \text {. }
$$

$\mathrm{У}$ табл. 3 наведено початкові та розрахункові дані, необхідні для визначення коефіцієнтів моделі для втом- ної міцності наплавлених зразків (без рідини) залежно від параметрів електроду.

За формулами (2) визначаємо коефіцієнти моделі:

$$
\begin{gathered}
a^{\prime}=\frac{-1,42 \cdot 4,66+4 \cdot 1,58}{(-1,42)^{2}-4 \cdot 1,32}=\frac{-6,52+6,32}{2,02-5,28}=\frac{-0,3}{-3,26}=0,09 ; \\
b=\frac{1}{4}(4,66+0,09 \cdot 1,42)=\frac{4,66+0,13}{4}=1,2 .
\end{gathered}
$$

Тоді $\hat{y}_{i}^{\prime}=0,09+1,2 x^{\prime}$.

Оцінку якості цієї моделі проведемо, визначивши коефіцієнт кореляції. Дані для його розрахунку наведено у табл. 4.

Табл. 3. Початкові дані для розрахунку коефіціснтів моделі для втомної міцності

\begin{tabular}{|c|c|c|c|c|c|}
\hline$x_{i}$ & $\lg x_{i}$ & $y_{i}$ & $\lg y_{i}$ & $\lg x_{i} \lg y_{i}$ & $\lg x_{i}^{2}$ \\
\hline 0,08 & $-1,1$ & 11,7 & 1,08 & $-1,19$ & 1,21 \\
\hline 0,5 & $-0,3$ & 15,8 & 1,20 & $-0,36$ & 0,09 \\
\hline 0,8 & $-0,1$ & 15,8 & 1,20 & $-0,12$ & 0,01 \\
\hline 1,2 & 0,08 & 15 & 1,18 & 0,09 & 0,0064 \\
\hline- & $-1,42$ & 58,3 & 4,66 & $-1,58$ & 1,32 \\
\hline \multicolumn{7}{|c|}{$\hat{y}=58,3 / 4=14,58-$ середне значення. } \\
\hline
\end{tabular}

Табл. 4. Початкові дані для розрахунку коефіціснтів кореляції

\begin{tabular}{|c|c|c|c|c|c|c|c|}
\hline$y_{i}^{\prime}$ & $y_{i}$ & $\hat{y}_{i}^{\prime}$ & $\hat{y}_{i}$ & $y_{i}-\bar{y}$ & $\left(y_{i}-\bar{y}\right)^{2}$ & $y_{i}-\hat{y}_{i}$ & $\left(y_{i}-\hat{y}_{i}\right)^{2}$ \\
\hline 1,08 & 11,7 & 1,39 & 12,6 & $-2,88$ & 8,29 & $-0,9$ & 0,81 \\
\hline 1,2 & 15,8 & 1,53 & 14,8 & 1,22 & 1,49 & 1,0 & 1,0 \\
\hline 1,2 & 15,8 & 1,53 & 15,8 & 1,22 & 1,49 & 0,3 & 0,09 \\
\hline 1,18 & 15,0 & 1,50 & 16,2 & 0,15 & 0,02 & $-1,2$ & 1,44 \\
\hline- & - & - & - & - & 11,29 & - & 3,34 \\
\hline
\end{tabular}

Згідно 3 даними табл. 4 , загальна $\sigma_{y}^{2}$ та залишкова $\sigma_{0}^{2}$ дисперсії відповідно однакові

$$
\sigma_{y}^{2}=11,29 \text { i } \sigma_{0}^{2}=3,34 .
$$

Розраховуємо факторну дисперсію

$$
\sigma_{\hat{y}}^{2}=\sigma_{y}^{2}-\sigma_{0}^{2}=11,29-3,34=7,95 .
$$

Тоді коефіцієнт детермінації

$$
K_{\text {д }}=\frac{7,95}{11,29}=0,704,
$$

тобто 70,4 \% зміни втомної міцності наплавлених зразків зумовлено зміною електроду, а 29,6 \% - впливом інших неврахованих чинників.

Коефіцієнт кореляції

$$
R=\sqrt{K_{\text {Д }}}=\sqrt{0,704}=0,84,
$$

що свідчить про щільність зв'язку між змінними $(R>0,7)$ і близькість реальної залежності $y(x)$ до степеневої $y=a x^{b}$.

Аналіз функціональної залежності 2, наведеної на рис. 1, дає змогу припустити, що це параболічна залежність і математична модель процесу

$$
\hat{y}=a+b x+c x^{2} .
$$

Для отримання коефіцієнтів моделі $a, 6, c$ на підставі експериментальних даних (див. рис. 1) складаємо систему рівнянь й за допомогою правил Крамера знаходимо розв'язок - коефіцієнти моделі [5]:

$$
a=\frac{\Delta_{1}}{\Delta} ; b=\frac{\Delta_{2}}{\Delta} ; c=\frac{\Delta_{3}}{\Delta},
$$

де: $\Delta, \Delta_{1}, \Delta_{2}, \Delta_{3}-$ відповідні визначники, складені з коефіцієнтів системи

$$
\left\{\begin{array}{l}
5,5=a+0,1 b+0,01 c \\
6,3=a+0,5 b+0,25 c \\
12,5=a+b+c
\end{array} ;\right.
$$

$$
\begin{gathered}
\Delta=\left|\begin{array}{ccc}
1 & 0,1 & 0,01 \\
1 & 0,5 & 0,25 \\
1 & 1 & 1
\end{array}\right|=0,180 ; \Delta_{1}=\left|\begin{array}{ccc}
5,5 & 0,1 & 0,01 \\
6,3 & 0,5 & 0,25 \\
12,5 & 1 & 1
\end{array}\right|=1,058 ; \\
\Delta_{2}=\left|\begin{array}{ccc}
1 & 5,5 & 0,01 \\
1 & 6,3 & 0,25 \\
1 & 12,5 & 1
\end{array}\right|=-0,888 ; \Delta_{3}=\left|\begin{array}{ccc}
1 & 0,1 & 5,5 \\
1 & 0,5 & 6,3 \\
1 & 1 & 12,5
\end{array}\right|=2,080 . \\
\text { Тоді: } a=\frac{1,058}{0,18}=5,878 ; b=\frac{-0,888}{0,18}=-4,933 ; \\
c=\frac{2,080}{0,18}=11,556 .
\end{gathered}
$$

і математична модель має такий вигляд:

$$
\hat{y}=5,878-4,933 x+11,556 x^{2} .
$$

Для перевірки правильності прийнятої гіпотези про параболічну функціональну залежність між змінними розраховуємо коефіцієнт кореляції. Необхідні для розрахунку коефіцієнта кореляції $R$ початкові дані наведено у табл. 5.

Табл. 5. Початкові дані для розрахунку коефіцієнта кореляції

\begin{tabular}{|c|c|c|c|c|c|c|}
\hline$x_{i}$ & $y_{i}$ & $\hat{y}_{i}$ & $y_{i}-\hat{y}_{i}$ & $\left(y_{i}-\hat{y}_{i}\right)^{2}$ & $y_{i}-\bar{y}_{i}$ & $\left(y_{i}-\bar{y}_{i}\right)^{2}$ \\
\hline 0,1 & 5,4 & 5,50 & $-0,1$ & 0,01 & $-4,05$ & 16,4 \\
\hline 0,5 & 7,5 & 6,30 & 1,2 & 1,44 & $-1,95$ & 3,80 \\
\hline 0,8 & 8,3 & 9,33 & $-1,03$ & 1,05 & $-1,15$ & 1,32 \\
\hline 1,2 & 16,6 & 16,6 & 0 & 0 & 7,15 & 51,12 \\
\hline & 37,8 & & & 2,50 & - & 72,65 \\
\hline & $\bar{y}=\frac{37,8}{4}=9,45$ & - & - & 2,50 & & \\
\hline
\end{tabular}

Для оцінювання моделі використовуємо:

- загальну дисперсію $\sigma_{y}^{2}=\frac{72,65}{4}=18,16$; 
- залишкову дисперсію $\sigma_{0}^{2}=\frac{2,50}{4}=0,62$;

- факторну дисперсію $\sigma_{y}^{2}=18,16-0,62=17,54$.

Коефіцієнт детермінації

$$
K_{д}=\frac{17,54}{18,16}=0,966 .
$$

Фізично він характеризує частку впливу вибраної змінної $x(97 \%)$ у загальній дисперсії.

Коефіцієнт кореляції

$$
R=\sqrt{K_{д}}=\sqrt{0,966}=0,983 .
$$

Оскільки $R>0,7$, то гіпотеза про параболічний зв'язок між змінними $x$ i $y$ підтверджується і ця модель дає змогу визначити втомну міцність наплавлених 3 охолоджувальною рідиною зразків залежно від вмісту вуглецю в електроді.

\section{Висновки}

1. На підставі експериментальних даних створено лінійну модель для визначення твердості наплавлених покрить залежно від марки електроду та його довкільного середовища.

2. Аналогічно побудовано модель, яка вказує на параболічний зв'язок між змінними й дає змогу визначити втомну міцність наплавлених шарів деталей 3 охолодженням залежно від вмісту вуглецю в електроді та його довкільного середовища.

3. Створені математичні моделі адекватно описують досліджувані процеси, оскільки розраховані коефіцієнти кореляції $R>0,7$.

\section{References}

1. Dotsenko, N. I. (1985). Vosstanovlenie kolenchatyih valov avtomaticheskoy naplavkoy. Moscow: Transport, 68 p. [In Russian].

2. Drohomyretska, Kh. T., Rybytska, O. M., Sliusarchuk, O. Z. et al. (2012). Teoriia ymovirnostei ta matematychna statystyka. Lviv: Vyd-vo NU "Lvivska politekhnikam 396 p. [In Ukrainian].

3. Goncharov, V. G. \& Savchenkov, B. V. (2003). Issledovanie iznosostojkosti stalnykh kolenchatykh valov. Visnyk KhDTUSH, 17, 71-76. [In Russian].

4. Kassov, V. D. \& Razumovich, O. O. (2014). Matematicheskoe modelirovanie sostava metalla, napravlennogo poroshkovoj provolokovoj slozhnoj konstrukczii. Visnyk KhDTUSH, 65-66, 131134. [In Russian].

5. Klepko, V. Yu., \& Holets, V. L. (2009). Vyshcha matematyka v prykladakh i zadachakh. Kyiv: Tsentr uchbovoi literatury, 594 p. [In Ukrainian]

6. Podrigalo, M. A., Goncharov, V. G., \& Savchenkov, B. V. (2003). Povyshenie nadezhnosti kolenchatykh valov dizelnykh dvigatelej naneseniem diskretnykh pokrytij. Visnyk NTU "KhPI", 4, 115-123. [In Russian].

7. Podrigalo, M. A., Goncharov, V. G., \& Savchenkov, B. V. (2004). Metody uprochneniya diskretnymi pokrytiyami sheek kolenchatykh valov avtomobilej dlya povysheniya resursa ikh raboty. Mir tekhniki i tekhnologii, 10, 52-55. [In Russian].

8. Polianskyi, O. S., Savchenkov, B. V. \& Baitsur, M. V. (2012). Tekhnolohiia vidnovlennia detalei ta remontu avtomobiliv. Kharkiv: Vyd-vo KhNADU, 320 p. [In Ukrainian].

9. Savchenkov, B. V., Goncharov, V. G., Aleksandrov, N. G. \& Samsonik, A. L. (2005). Vliyanie rezhimov diskretnogo uprochneniya na ekspluataczionnye svojstva detalej avtomobilej. $A v$ tomobilnyj transport, 16, 83-85. [In Russian].

G. S. Gudz', M. I. Herys' ${ }^{2}$ I. Ia. Zakhara ${ }^{3}$, M. M. Ostashuk ${ }^{1}$

${ }^{1}$ Lviv Polytechnic National University, Lviv, Ukraine

${ }^{2}$ Ukrainian National Forestry University, Lviv, Ukraine

${ }^{3}$ Ivano-Frankivsk National Technical University of Oil and Gas, Ivano-Frankivsk, Ukraine

\section{MODELS FOR DETERMINING THE EFFECT OF CARBON CONTENT IN THE ELECTRODE ON THE PROPERTIES OF MACHINE PARTS DURING ELECTRIC ARC CLADDING}

The repairing and subsequent use of worn and damaged parts is one of the important factors for the technical and economic efficiency of machine repair. In the course of the research, coating of part surfaces with a layer of metal of the required thickness, followed by mechanical treatment of the surface to a nominal size, is defined to be one of the most common methods of restoring the original size of the parts. The deposition of a metal layer is carried out by various methods of cladding, among which the cladding of parts with a vibrating electrode by means of an automatic head with the use of coolant is found to be quite effective one. One of the advantages of this method in comparison with others is the ability to apply hard coatings 1-2 $\mathrm{mm}$ thick, as it does not have a significant thermal effect on the parent metal and has a high performance as well. The deposition in the atmosphere of air and the protective gases at low voltage $(10-12 \mathrm{~V})$ is found to be accompanied by poor fusion of the deposited and base metal. The fusion strength also decreases with decreasing carbon content in the electrode. This is facilitated by the considerable oxidation of the molten metal. With the increase of carbon content in the wire, due to its partial combustion during cladding, there is some protection of the metal from oxidation. Alloying metals during cladding in the coolant stream is usually good, which indicates the high intensity of the process in the alloying zone of the electrode and the part, although no significant heating of the part is observed. The use of coolant is considered to be accompanied by both positive and negative phenomena. The positive features are such as the rapid formation of weld metal, its hardening and wear-resistant structure, cooling the workpiece and preventing its deformation, as well as some protection of the metal from oxidation. Negative phenomenon of cladding in a liquid should be considered heterogeneity of structure and hardness, presence of pores and microcracks, which leads to reduction of fatigue strength and is undesirable for the parts of machines with alternating loads. Therefore, the dependence of the fatigue and surface hardness of the workpiece using electrodes with different carbon content and cooling schemes, which are obtained in our research, are of considerable interest for engineering practice. Due to elaboration of the empirical dependence of the hardness of the surface of the clad parts on the carbon content in the electrode, a linear model was constructed, and a parabolic model was constructed for the workpice fatigue strength on the carbon content. The reliability of the obtained models is confirmed by the calculated correlation coefficients.

Keywords: repairing of machine parts; cladding of workpiece surfaces; surface hardness; workpiece fatigue strength; linear and nonlinear mathematical models. 